\title{
Issues of Gender Equality and Diversity in Broadcast News Policy
}

\author{
KRISTINA WIDESTEDT
}

\begin{abstract}
The objective of this article is to investigate the relationship between concerns for diversity and concerns for gender equality in broadcasting companies from Sweden, the UK and the US. This is carried out through analyses of policy documents accessible on the companies' websites. The contents of the policies and their definitions of diversity are discussed in a context of gender equality and multiculturalism. The concluding results of the study indicate national differences in definitions and applications of diversity, but also, and more importantly, a similar tendency in all three countries to subordinate concerns for gender equality to concerns for diversity.
\end{abstract}

Keywords: broadcasting companies, diversity, gender equality, policy

\section{Introduction}

In early twenty-first century Europe, "multicultural society" has become a standard definition of modern nations, used nearly always in a positive sense, indicating an enrichment of social and cultural diversity. The reverse interpretation, connecting multiculturalism to potential conflicts and clashes of group interests, is a perspective often equated to racism, and therefore taboo in mainstream political discourse. This article is based on two main arguments:

1. A rigid polarization of positive versus negative opinions on multiculturalism might actually harm the development of multicultural coexistence, by denying the existence of opposing interests in society at large. This constitutes a conflict within the diversity debate that has to be dealt with rather than ignored.

2. The tendency to delegitimize any opposition to the multicultural society might be damaging also to the accomplishments of the feminist movement. When concerns for diversity and concerns for gender equality come into conflict, feminists run the risk of being posed alongside racists as adversaries to the multicultural society.

In the present study, I examine the relationship between diversity and gender equality as expressed in policy documents from six broadcasting companies. I wish to underline the importance of an open debate on conflicting group interests, a conflict-sensitive debate aimed at working through rather than quenching disagreements and dissatisfaction among the inhabitants of the multicultural society. 
Seyla Benhabib, in her book The Claims of Culture (2002), also underlines the need for nuanced perspectives in the multiculturalism debate. She discusses two different views on multiculturalism. On the one hand, there is the concept of mosaic multiculturalism, which assumes that different cultures have clear and stable demarcations that enable them to mix harmoniously into a colorful mosaic pattern in the multicultural society. On the other hand, Benhabib puts forward the opposing idea of a dialogic multiculturalism, which recognizes and gives scope for possibilities of change and mutual adaptation between cultures, resulting in a melting pot rather than a mosaic. This perspective is more sensitive to the problems of the multicultural society in that it acknowledges the unpredictable directions that social and cultural changes may take and the obvious risk that the majority culture, as well as minority cultures, may be subject to transformation. However, Benhabib avoids delving deeper into this discussion, something that strengthens her theoretical argument but threatens to undermine its political possibilities.

Whether or not we agree that the multicultural society is predominantly characterized by its diversity, this remains a vague term that seems to cover anything from the assortment of magazines in local supermarkets to the variety of political opinion in national parliaments. Diversity as a political concept is closely linked to neo-liberalist theory and frequently used to describe the all-pervasive plurality of market-driven societies, as if diversity always means the possibility for everyone to choose their favorite alternative. The consumerist definition of diversity reappears in discussions of media output, implying unlimited freedom of choice for the individual media consumer, but at the same time facing media producers with the problem of fragmented audiences. Post-modern social theory extends the scope of diversity to the psychological realm, stressing the positive aspects of modern individuals' constant self-reflexivity and the resulting construction of multidimensional identities, while at the same time acknowledging the risk of ending up in a condition of permanent indecisiveness and even existential anxiety (Giddens 1991: 32ff).

Summing up the above, it is difficult to get a clear idea of what diversity is, and whether it is good or bad. This conceptual and normative vagueness, however, does not seem to affect the political value of diversity. Consequently, when cultural and ethnic diversity as a general political objective is imposed on media politics and policies, considerable confusion is the result. Regardless of whether one adopts a commercial or a psychological frame of interpretation, diversity can hardly be regarded as solely positive. Nevertheless this seems to be exactly what happens in the formation of diversity policies: The positive aspects of the concept are fully embraced, while the negative aspects are disregarded.

The diversity issue is much too complex and important to be treated in a simplifying way. Arguably, the politics of ethnic and cultural diversity, whether within or outside of the media, demands a concrete plan of action and raises several questions to reflect upon. What kind of diversity do we want? Where do we want diversity to lead us? Are we satisfied with enjoying the stable pattern of the multicultural mosaic, or are we willing to transform in the multicultural melting pot? And how do we prefer integration to be achieved - by assimilation or by differentiation?

Charles Husband (2000) regards assimilation politics as a way of constructing an oldfashioned society, an "imagined community" (Anderson 1991) in which everybody consensually strives for mutual goals like the common good, public welfare, etc. This does not apply any more, Husband states. Assimilation politics may be functional in societies with very low levels of immigration, but does not accord with increasing de- 
mands for group rights in today's multicultural societies. According to Husband, the most important task is rather to enable multi-directional communication flows between different groups. He puts forward "the right to be understood" as an addition to the fundamental democratic rights of every citizen. This involves the necessary assistance of the media, and will ultimately lead to a melting pot culture in that the right to be understood implies a dialogic inter-group communication.

Provided that multiculture and diversity are not identical concepts, however, a wider definition of diversity should be considered, inclusive of gender and class perspectives. This, in turn, calls for an even greater readiness to deal with potential conflicts. The problems of diversity need to be solved instead of being denied.

\section{Diversity and the Media}

Broadcast media with a nation-wide audience have a special position in this context their wide reach is accompanied by a responsibility towards subordinated groups in society. Public service media in particular are committed to finding a balance between assimilation and differentiation. On the one hand, they are supposed to perform the traditional tasks of national media companies, uniting the nation and promoting positive feelings of national community (cf. Scannell 1989). On the other hand, they should work for diversity on every organizational level, locally as well as globally, from the ownership of media corporations to the presentation of news items in different newscasts. They are also supposed to produce programs in minority languages, buy programs from all over the world and compete successfully on a commercial market.

Commercial broadcasting companies act on a different arena. Their primary concerns are not for assimilation or differentiation as such, but for conducting profitable business. In that context, differentiating between minorities is probably not on the agenda, considering that the big money comes with numerous audiences. The only kind of commercially viable differentiation is the meticulous targeting of specific age/income/gender groups within the media audience at large, a crucial part of the ratings competition. However, the political idea (or ideal) of diversity might quite easily be converted into a crypto-commercial concept, a "bonus value" adopted by otherwise strictly profitmaking companies not for humanitarian reasons, but in order to make even more money, to "sell" the company as politically conscious and correct.

\section{The Politics of Representation}

In media theory, the diversity issue has been studied as a politics of representation (cf. Hall 1997), which concerns the presence of particular groups in the media output as well as in the process of media production. This connection between media representations and politics signals the great importance of representation in contemporary media-saturated society, where any kind of group has all but a democratic right to be given voices and faces in the media output. This certainly motivates a conscious politics of representation in media companies.

But how should this media representation of groups be achieved - in accurate proportion to the total population, or according to some ideal justice or utopia? And who should carry it out - journalists from a majority group, displaying minority members to the general public, or journalists from minority groups? In that case, who are the audience? Husband (2000) argues that a billion minority media do not make a difference unless they are directed at the general public as well as at minorities. If democracy is 
to function, there must be some sort of dialogic exchange between the majority and minorities.

This point taken, the question of which groups should be singled out as politically "legitimate" minorities still remains. Several important distinctions are drawn on this level. This has a bearing on the actual representation of these groups in mainstream news media, where politically legitimate groups are more visible than others. In other words, the politics of representation can be seen to work both ways: Political decisions concerning minorities influence media representation, and media representations of minorities contribute to the political empowerment of these groups.

The politics of representation is connected to an idea of representativity, similar to the principles of parliamentary democracy. According to these principles, the general public is divided into a number of distinct categories, from which a statistically representative population can be composed. Creating a balanced representation of the general public is obviously a problem. There is always the risk that some categories, characteristics or groups will stand out as more important than others.

The introduction of the concept of diversity into political discourse has first and foremost meant a collective effort to avoid nationalist biases and correct ethnic imbalances in political as well as media systems of representation. Arguably, this duplicates the process of changes that accompanied the breakthrough of gender equality in the 1970s. This might be one reason why gender tends to be left out of the diversity debate - the issue of gender equality is considered more or less settled.

Law-making being the dominant political way of dealing with diversity, one might ask what this means in practice. How do media companies - public service and commercial - deal with diversity issues on a policy level? How do they account for their actual diversity work? And in what ways is gender equality related to concerns for diversity?

\section{Diversity Policies in Media Companies}

Starting from these questions, the following accounts for a study of six media companies: Sveriges Television (SVT) and Sveriges Radio (SR) in Sweden, BBC and ITV in the UK, and CBS and Fox in the US. Their common denominators, as well as the criteria of selection, are two:

a) Each company produces news programs of nationwide and/or international reach.

b) The information available on the companies' own websites includes policy statements on diversity and/or gender equality.

As information of potentially global reach, the material on these websites is of great importance. The media companies' policy documents perform several functions at once: a normative function towards their employees, providing guidelines and strategies for output and staffing; a pragmatic function towards state authorities, demonstrating the companies' readiness to play by the political rules and regulations for national broadcasting; and finally a promotional function towards the audience, displaying the companies' concern for every group in society.

In their book Representing 'race': racism, ethnicities and media, John Downing and Charles Husband include a section on media monitoring, media performance and codes of practice in relation to ethnic diversity (Downing \& Husband 2005: 145ff). They argue that these codes in fact constitute a "gestural rhetoric" of professional standards, 
representing desired values ("the collectively imaginable") rather than regulating behavior and action ("the collectively attainable"). I wish to add that policy documents are always political and thereby contain implicit promises of responsibility and performativity. Policies that do not include practical information on how the companies work to reach their aims are therefore of little or no value.

\section{Brief Facts about the Companies}

SVT (Sveriges Television): Sweden's largest media company, the only public service television company in Sweden. Broadcasting in four national channels and one European channel.

SR (Sveriges Radio): Sweden's public service radio company, broadcasting in four national channels and one international channel, to an average audience of four million daily.

BBC (British Broadcasting Corporation): The largest broadcasting company in the UK, producing television as well as radio on a partly public service, partly commercial basis. Television is broadcast in eight national (public service) channels and ten international (commercial) channels, and public service radio in ten national channels and one international channel (the BBC World Service, available in 43 languages).

ITV (Independent Television): The largest commercial television network in the UK, voluntarily subject to public service regulation, broadcasting in five national channels.

Fox: Part of the global media conglomerate News Corporation. Producer of movies and TV entertainment, also broadcasting news and current affairs in one international television channel (Fox News Channel) and in national radio stations.

CBS (Columbia Broadcast System): One of the legendary 'three giants' of US broadcasting, established as a radio network in 1930, now producing news and entertainment for national and international television.

\section{Empirical Findings}

The companies' websites have been explored with regard to the following aspects:

1. In what way is diversity an issue to the company?

2. Which groups/categories are explicitly mentioned in connection with diversity?

3. In what way is gender equality an issue?

4. How are diversity and gender equality combined?

The search terms for the analyses of these websites were "diversity" and "equality". Only "diversity" gave any substantial results. Quantitatively speaking, at least in terms of discursive space, concerns for diversity completely overshadow gender equality issues.

\section{SVT}

Since 2004, SVT has established an annual official policy for ethnic and cultural diversity (available in English via http://svt.se/svt/jsp/Crosslink.jsp?d=37123\&lid=About_SVT), comprising guidelines for programming and staffing. In the policy, diversity is explic- 
itly defined as an ethnic and cultural concern. As early as page 3, however, the reader learns that the Radio and Television Law requires that SVT work towards:

condemning racism, violence and brutality and maintaining equality between men and women.

This implies an equal standing between diversity and gender equality. Matters of gender equality, however, are not included in the diversity policy, but treated in a separate policy document, which is not available on the web.

In its outlines of aims and restrictions for employment and programming, the document also allows for interpretation of SVT's position in Swedish society. For example, page 4 in the policy expresses SVT's commitment to be a "major player in developing a society of ethnic and cultural diversity". This indicates a consensus-dominated model of national community. Accordingly, the policy ( $\mathrm{p}$ 5) also expresses a commitment to "depict and examine the integration process in Sweden and other countries", apparently based on an assimilationist politics, dismissing actual and potential social conflicts. However, other phrases in the document (p 5) treat the issue from another point of view, setting out to

- Reflect and depict inter-cultural encounters.

- Question traditional views through depiction and investigation aimed at increasing knowledge about, and understanding among, people of different ethnic and cultural backgrounds.

These statements indicate a differentiation-friendly perspective, which dominates the rest of the document. Thus, we learn that diversity in staff should be achieved by regarding "multicultural qualifications, proficiency and experience" (that is, an immigrant background) as assets to the company, and by strictly adhering to the principle of equal treatment "regardless of ethnicity, religion or creed".

The company's commitments to diversity have been implemented in a special Multicultural Centre, a two-year project (2003-2005) intended to increase ethnic and cultural diversity in programming as well as in staff. SVT's explicit concerns for diversity include people of diverse ethnic affiliations, religious beliefs and cultural backgrounds. However, neither disabled people, sexual minorities nor women are addressed in the company's diversity policy. And in the end, professional ideals of neutrality and objectivity turn out to be superior to diversity commitments, as stated in the dress code (p 7):

As television is a visual medium and the image essential to the communication of information, programme presenters are to wear clothing that does not distract the viewers from the intended content of the broadcast. Decisions on clothing are made from case to case.

To sum up, the diversity code for SVT is undoubtedly politically motivated, in line with public service television's compliance to state regulations. However, the actual standpoint of the company seems ambiguous: While the staffing policy obviously adheres to a differentiation ideal, the output of programs seems to aim for ethnic assimilation on a national level. I wish to argue that this is because SVT perceives itself as a state authority. The public service output is in fact regarded as a compulsory component of the construction of Swedishness and Swedish identity, in the sense that Swedish culture and dominating collective values are taught to native Swedes and immigrants alike by SVT. 
In order to gain access to the inner workings of the company and be part of the workforce, it is necessary to fulfill the demands of Swedish cultural competency - and only in addition to this are "multicultural" competencies considered.

SVT's concerns for gender equality seem to be overshadowed by diversity matters. Arguably, diversity is currently a more contested and debated political issue than gender equality, and can therefore be considered a more rewarding subject upon which to spend time and resources. The absence of gender in the diversity policy, however, implies a lack of knowledge about (or disbelief in) the inherent level of conflict between different power structures.

\section{$S R$}

$\mathrm{SR}$, Swedish public service radio, is the largest radio company in Sweden. Its diversity policy, available (in Swedish) on http://www.sr.se/omsr/om_public_service/ mangfaldspolicy/policy.stm, concerns primarily the issue of cultural diversity, which is explicitly connected to the multicultural society. The policy opens with three statements:

Cultural diversity - enriches the output

Cultural diversity - takes advantage of human resources

Cultural diversity - increases tolerance and counteracts prejudice

This positive attitude towards the potential of systematically developed cultural diversity characterizes the policy in its entirety. The company repeatedly states its commitment to "reflecting" the multicultural society through its programs as well as through its recruitment of staff. Nowhere are there any hints of criticizing or scrutinizing the multicultural society, which reveals a strong adherence to the social responsibility of public service ideology - the media should cooperate with parliament and government in maintaining harmony and stability in society.

The open-ended meaning of "cultural diversity" is restricted, however, when it comes to the actual measures taken to increase diversity in the company. It appears that cultural diversity, in programming as well as in staff, is provided exclusively by persons with "immigrant/ethnic backgrounds" - as if native Swedes did not have an ethnic background. Other varieties of culture (gay culture, Muslim culture, etc.) are not mentioned, neither are any other categories distinguished. Consequently, gender issues are completely absent in connection with diversity, despite a long tradition of equality work in SR. This implies that problems of gender inequality are considered a thing of the past, irrelevant in a modern, multicultural society.

When the concept of diversity is equated with non-Swedish ethnicity, the possibilities of cultural and social differentiation narrow considerably. This limited interpretation of diversity may be explained by the deeply forged nationalist traditions of all public service broadcasting institutions; nation and nationality being the main original devices used when establishing media companies on a public service basis, and therefore central to recent conceptions of public service media as well.

In the company's annual staffing report, however, the age and gender composition of the entire workforce is examined and accounted for in several contexts, such as the distribution of sick leave and parental leave but also the range of occupational areas and statuses within the company (http://www.sr.se/cgi-bin/mall/artikel.asp?programID= 2350\&Artikel=741492). There are no traces of ethnicity in this report, which is inter- 
esting and quite challenging in connection with the company's progressive diversity policy. Placed within a pragmatic political context, however, this is more understandable: It is simply not possible to produce statistics based on ethnicities without being accused of racism or xenophobia.

On the level of policy-making, the issue of multiculturalism obviously occupies a central space, whereas gender equality perspectives pervade the internal assessment of performance. The immediate conclusion is that SR does not possess any tools for measuring and evaluating the degree of multiculturalism in the company. Also, gender equality and diversity are kept strictly apart, being discussed neither at the same time nor in the same context. This might create a false impression that both issues are unproblematic and quite possible to deal with in a practical, hands-on manner. Rather, it is quite obvious that SR's diversity policy illustrates the dilemma defined by Downing and Husband (2005): vainly trying to bridge the gap between the collectively imaginable (diversity as an ideal) and the collectively attainable (diversity as practice).

\section{$B B C$}

The BBC confesses to a very detailed definition of diversity in its diversity policy (http:/ /www.bbc.co.uk/info/policies/diversity.shtml):

The $\mathrm{BBC}$ is committed to reflecting the diversity of the UK and to making its services accessible to all. This applies both to the output - TV, radio and online - and the workforce, aiming to be inclusive of those groups who are often under-represented - older people, women, disabled people, people from ethnic minorities, those of all faiths and social classes, lesbians and gay men.

It is worth noticing that the BBC includes social class, age, sexuality and gender on their diversity list, besides the ethnic and religious minorities. This conception of diversity is obviously wider than the Swedish. However, apart from this declaration, not much more is said about the contents of the diversity policy on the website.

Interested readers can indulge in the long and detailed BBC Annual Report (http:// www.bbcgovernors.co.uk/annreport/index.html), where the Governors of the company evaluate its commitments and objectives on a yearly basis, in a section called "Governors' review of objectives". This section reappears every year in the report, but is structured differently depending on the objectives set out for the year in question. The latest studied report (2004/2005) pays little attention to issues of diversity and equality, stating merely that the company continues to monitor the diversity of staff, and that a new diversity strategy suggests a redirection of efforts from being target-driven to being "more culturally supportive of staff diversity, and using diversity to connect better to diverse audiences".

The annual report for 2003/2004, however, was significantly more rewarding for the purposes of this study, as diversity and representativity were in focus in several of the company's objectives that particular year. The Governors' assessment of the output for 2003/2004 concerned three audience categories: younger audiences (16-34 years of age), ethnic minorities and local/regional audiences throughout the UK. They concluded that:

a) The reach among the younger audiences has increased by 1.5 points to $90.5 \%$, mainly thanks to drama and soaps. News and current affairs, however, are attracting a mere $10 \%$ of the age group, primarily via the $\mathrm{BBC}$ website 
(bbc.co.uk/news), and the continuing efforts to engage young audiences in politics have more or less failed.

b) The ethnic minorities' approval of BBC output has improved, but the company's reach among ethnic minorities is "significantly lower" (no numbers) than among the general population.

c) The local/regional audiences are targeted with locally or regionally produced output, as well as with special BBC events and activities increasing the physical presence of the $\mathrm{BBC}$ in towns and cities across the UK. The latter initiatives have succeeded in bringing the company in contact with new audiences (ethnic minorities and "the under-45s"), but the local/regional output is still disfavoured in terms of television sending time.

These results are not particularly impressive as such. Yes, young people are watching the $\mathrm{BBC}$ - but only its entertainment programs, not its educational and political contents. Ethnic minorities do not disapprove of the company - but they do not choose BBC programs as often as the general population do. Add to this that the output for local/ regional UK audiences is regularly scheduled at off-peak viewing time, and there seems to be only scarce traces of actual and influential diversity in the overall output.

Concerning staff, the Governors' review acknowledged the company's efforts to "reflect the diverse society it serves", and stated its recent meeting of the

target of $10 \%$ of its total workforce and $4 \%$ of senior management coming from ethnic minorities by December 2003.

This target is higher than the ethnic minorities' overall representation in the UK (estimated to $7.9 \%$ ), which is justified by the argument that the BBC is located in large urban areas with a concentration of ethnic minorities. A long-term target of $12.5 \%$ ethnic minorities in staff and $7 \%$ in senior management is set for the end of 2007 . We learn that $50 \%$ of staff and $37 \%$ of senior management are women (these figures are not matched with the general population), and that $2.7 \%$ of staff are disabled people, "close to the $3 \%$ recorded for the media industry as a whole", but with no information about the proportion of disabled people in the audience as a whole. The ambition to exceed the industry-wide figure "in future" was clearly stated. Concerning age, 79\% of BBC staff are younger than 45 years, and $96 \%$ are under 55 . This is significantly different from the audience as well as from the UK workforce as a whole. The staff's having "a younger age profile than the audience they serve" has induced a research project to "improve the company's understanding" of older audiences, but has not led to any changes in the actual age profile of the staff.

In all these accounts of representativity, there are no objectives concerning the representation of diverse social classes and religious faiths, despite the diversity policy's all-inclusive opening statement. Neither are sexual minorities in any way represented in the Governors' review. This is similar to the situation in SR, where the policy level is more inclusive than the actions carried out in practice.

The BBC's ideal to be "representative of the audiences it serves" is strictly measured by numbers. As argued earlier, such statistical representations are rather inflexible constructions that tend to disregard, for example, the widely spread experience of having multidimensional identities. In that sense, representation by numbers and quotas can hardly reflect a complex society. 
In a similar vein to SVT, the BBC employs a nationalist rhetoric, trying to cater to the needs and demands of all parts and groups of the UK, though not necessarily all at once. The proportional representativity of various groups in the workforce is ascribed considerable importance, seemingly aiming at creating a miniature replica of the nation within the company walls with regard to categories such as gender, ethnicity, age and disability - but leaving out more provocative categorizations based on social class, sexual orientation or religious belief. This, of course, is completely in accordance with the unifying and consensual ethos of national public service media.

\section{ITV}

ITV is the largest commercial network and the most strictly regulated commercial broadcaster in the UK. The company considers that it is "making a major contribution to the UK's culture, economy and communities" (http://www.itv.com/page.asp?partid=1088), and directs its diversity concerns explicitly towards disabled people:

The ITV companies welcome diversity, both in our people and our programmes. We are strongly committed to raising awareness of disability issues, not least because both our audiences and advertisers expect us to reflect the diversity of the UK population on screen.

Monitoring of representativeness has been undertaken within ITV companies, and where inequalities become apparent, then as far as practical, positive action has been taken to redress the imbalance, for example through special training schemes or work placements designed to encourage applicants from underrepresented groups.

(http://www.itv.com/page.asp?PartID=1106\&depth=2, accessed 2005-11-01)

ITV's particular concern for the disabled stands out on its website, where "disability" is the only diversity category given a space of its own in the top frame of the page. The most probable reason for this profiling is the company's active participation in the establishment of the national Broadcasting and Creative Industries Disability Network, and its current (2005-06) chairing of the Cultural Diversity Network.

It is worth noting that advertisers' expectations are given an equal standing with the audience's demands on the company "to reflect the diversity of the UK population on screen". Evidently, advertisers do not care about diversity off screen, staff being of scarce commercial interest.

Due to the limited definition of diversity, neither ethnicity nor gender is mentioned on the ITV website, and gender equality issues are absent as well. However, in ITV1's 2004 Review (accessible via http://www.itv.com/page.asp?PartID=1145\&depth=2), diversity is equated with cultural diversity and illustrated with photographs of darkskinned actors and the odd non-white studio anchor. Gender equality remains outside the discussion.

All in all, ITV demonstrates its adherence to a commercial and competitive conception of diversity by more or less hijacking the disabled and directing its diversity work at them - an action clearly advantageous to the company's profile. 


\section{CBS}

To CBS, diversity is obviously an important issue, something that calls for responsible action from the company as a significant actor among national American media. In its "mission statement" on diversity, CBS explicitly expresses their desire to set positive examples for the entire media industry:

CBS is committed to building and nurturing a diversified environment throughout the entire company, as well as the entertainment industry at large.

Recognizing the power and influence the company carries through its nationwide reach of network programming and local television stations, CBS has been on the forefront of making diversity a reality through a wide array of workshops, talent showcases and internships designed to bring more minorities into the creative process, and to create opportunities where they may not have existed before.

Likewise, internally, CBS continues in its efforts to create a workplace that is representative of the American public, and which offers the same hopes, dreams and opportunities to all.

(http://www.cbscorporation.com/diversity/cbs_network/mission_statement.php)

There is also a vision of achieving pure democracy within the corporate walls, expressed in the idea of a workforce that, on the one hand, accurately represents "the American public" and, on the other hand, is given not only the same opportunities, but also the same dreams and hopes. Rhetoric aside, the only dreams and hopes that all employees at CBS can realistically share most likely come down to keeping their jobs and getting better paid. But of course, the opportunities for this within the company are probably not the same for all.

The desire to define diversity and apply it on an everyday basis in the company is expressed in an extremely detailed and inclusive description of possibly discriminating categories allegedly not taken into account when employing people at the CBS:

CBS Corporation places a high value on providing equal employment opportunity and maintaining a diverse workforce. We work hard to comply with all applicable laws prohibiting discrimination and we strive to make our workforce reflect the rich diversity of our society and our customers. CBS Corporation recruits and hires without regard to race, color, sex, religion, national origin, ethnicity, age, marital status, sexual orientation, gender identity, gender expression, disability, veteran status or any other basis prohibited by law. (http://www.cbscorporation. com/career/index.php)

If too many factors are considered legitimate ground for charges of discrimination, there is a considerable risk that the concept will be left completely devoid of its meaning as well as of its legal and political potency. There is also a risk that conservative opinions in separate questions will be equated with seriously problematic, structural issues such as racism and sexism. On the other hand, separate questions such as marital status, age and gender expression often turn out to be parts of a larger pattern, ending up in one or another of the structural issues anyway. So, assuming that this detailed definition of diversity is after all a good thing - on what grounds do CBS actually discriminate between their job applicants? Some kind of discrimination is obviously necessary, because they cannot possibly hire everyone. And is representativity at all possible with- 
out affirmative action, which actually demands that precisely the factors that CBS disregards be taken into account?

The company's actions on behalf of diversity include the CBS Diversity Institute, established in 2003, which finds and promotes talented people from various minority groups. One of their initiatives is the News Development Program, which works particularly to "identify and support promising journalists of color" (http://www.cbsnews.com/ stories/2004/08/03/broadcasts/ main633770.shtml).

The program started in January 2005 and aims at "even greater diversity in the newsroom". Two minority journalists are selected for the program each year, hired and given a personal mentor in an affiliate newsroom anywhere in the US. After two years of apprenticeship, the aim is to employ them on CBS News.

I have examined and made some calculations from the list of employees at CBS News on the web (http://www.cbsnews.com/stories/2002/10/17/utility/ main525997.shtml, accessed 2005-04-25). It turns out that:

a) CBS News has 104 employees

b) 45 are women

c) 10 employees are African-Americans, Asians, Hispanics or Arabs

d) 3 of these are women

e) 25 employees are in managerial or superior positions

f) 13 of these are women

g) none of the minority employees is in a managerial or superior position

This indicates that CBS News has succeeded with its gender equality work - a 40/60 balance between women and men is usually considered a sufficient outcome, and on the manager level as many as $50 \%$ are in fact women. When it comes to the representation of ethnic minorities in staff, however, the ratio is considerably smaller $-10 \%$, and no one in a managerial position. This taken into consideration, it seems that there really is a need for "greater diversity in the newsroom" at CBS.

Because women are not singled out as a category on the diversity website, there is a risk of losing them in the diversity work, which is supported by the fact that only 3 of the 10 minority journalists at CBS News are women. On the other hand, all 10 journalists are correspondents, which means that they are visible on screen and therefore able to play out their representative function in public. This kind of visual representation is probably of great importance for viewers' identification and role-model building.

Summing up, CBS adopts objectives similar to those of, for example, SVT and the $\mathrm{BBC}$ in striving to represent an entire national public. However, this is supposed to be achieved by disregarding all group-defining categories and basing all employment decisions on what must be described as an exclusively meritocratic principle, which emphasizes professional and systemic competence and sets its hopes for true diversity on the representativity of the random sample. 
FOX

FOX's website promotes the launching of its diversity policy a full six years after the actual event took place:

In a historic demonstration of FOX's commitment to expanding diverse representation in front of and behind the camera, our organization signed a Statement of Understanding with the NAACP [National Association of Advancement for Colored People] and its multi-cultural coalition partners in February of 2000 announcing a number of goals toward this end.

(http://www.fox.com/diversity/launch.htm)

Though not expressed directly, diversity on FOX seems to mean ethnic diversity only. Heavily charged words such as "historic" and "commitment" add to the ceremonial dignity of the described event when the statement was signed. This certainly raises expectations concerning the actual contents of the diversity statement as such, signed by the chairman of the FOX group. However, the statement stresses primarily the company's business strategy and competitiveness:

We believe our future rests in our collective ability to embrace change and leverage diversity through our leadership, productions, employment, procurement and continued community support. We believe that diversity is critical to our business strategy, and will improve our competitiveness and prospects for longterm success.

(http://www.fox.com/diversity/)

The vague limitation of "we" and "our" - from "we human beings" to "we the company" - indicates the global reach of the FOX Group, and makes basic humanist values ("our collective ability to embrace change and leverage diversity') seem a natural part of the company ideology. This impression is of course subdued by the profit-oriented discourse.

In connection with the implementation of its diversity policy, FOX created a Diversity Team (today consisting of four men and four women), responsible for "diversifying" network programming, recruitment, procurement and community outreach. The company's strategic plan for diversity development has one main goal - "to incorporate diverse voices into every aspect of our business" - and five sub-goals (http:// www.fox.com/diversity/plan.htm). In the plan, FOX does not actually promise anything besides "increasing" opportunities and representation of minorities (no numbers mentioned) and "demonstrating" its commitment to diversity (in unknown ways).

FOX's definition of diversity encompasses primarily certain ethnic minorities, derived from a national US context that is most explicitly expressed in connection with their procurement policy:

'Minority group members' are United States Citizens who are African Americans, Hispanic Americans, Native Americans and Asian-Pacific/Subcontinent Asian Americans.

(http://www.fox.com/diversity/procurement.htm)

It is difficult to find out anything about the results of FOX's diversity work, despite the amount of information accessible on the website. Under headings such as "creative efforts", "people", "internships", "outreach", "education" and "rankings", several disconnected diversity events are presented, all with one thing in common: They are aimed at 
African Americans and Hispanic Americans. It is not possible to discover whether the events accounted for are selected from a number of similar events, or whether they are the only initiatives of their kind.

The company's commercial view of diversity stands out clearly in the "rankings" section of the website (http://www.fox.com/diversity, accessed 2005-04-22). Dealing with audience ratings, separate statistical tables are devoted to viewers from the ethnic groups mentioned above, and accompanied with explaining comments:

As evidence of FOX's strong track record of delivering Hispanic viewers, we have consistently shown leadership in Hispanic viewership ratings. In fact, in the Summer 2002 Ratings Race, FOX was Number 1 with Hispanic Adults/ Women/Men 18-49, Adults/Men 18-34 and Teens 12-17 among the networks. In 2003, FOX's lead among Hispanic adults $18-49$ widened to $66 \%$ over $2^{\text {nd }}$ place NBC vs. a mere $1 \%$ margin this time last year.

FOX has also shown a consistent ability to reach African-American viewers. In fact, during the last four seasons, FOX shows have consistently ranked in the top 3 for African-American audiences.

Obviously, this text is aimed at advertisers rather than at people from ethnic minorities. The use of expressions such as "delivering Hispanic viewers", "leadership in ratings", and "Ratings Race" does not exactly testify to a social commitment to minority groups.

Neither is equality between the sexes an urgent issue on the FOX website. Women are briefly mentioned as business owners in connection with the so-called MWBE:s (Minority or Women-Owned Business Enterprises), but otherwise, potential gender injustices in various sections of the company are not discussed. The company seems more interested in purchasing services and products from female business owners than in promoting and supporting their women employees.

On the special FOXnews site (http://www.foxnews.com), there is no information about their reporters and news anchors, and no list of names and positions. Therefore, it is not possible to evaluate the outcomes of FOX's diversity policy in terms of the ethnicity and gender of their employees in a particular division of the company. In the rhetoric of FOX, diversity seems to largely be used as a PR device.

All in all, a consistently commercial interpretation of diversity is prominent on FOX's website. Audience diversity is used as a means of attracting advertisers rather than as a political objective per se, and the company's overall aim "to incorporate diverse voices into every aspect of our business" reminds us that FOX is above all a profit-making enterprise whose primary motivation for being in the broadcasting business is economical rather than political.

\section{Summing Up: International Comparisons of Diversity}

\section{Sweden: Multi-cultural Diversity}

The empirical analysis indicates that there are differences between Swedish, British and American interpretations and definitions of diversity. In the Swedish media context, diversity means ethnic and cultural diversity, and is frequently put forward as something that enriches social and professional life. No problems are indicated, neither of a practical nor a political nature. This focus on ethnicity should be related to the fact that the Swedish immigrant rate is the highest in Scandinavia, and that immigration policy is a 
continuously contested issue in Swedish public debate. In this context, it is easier to understand why ethnic and cultural diversity is so optimistically represented - there is a political line of action to defend. On the other hand, this one-dimensional description of the advantages of the multicultural society is bound to clash with harsh reality and the society's suburb ghettoes, unemployment, illegal workers, taxes and social security - which invites social unrest and complaints from citizens who feel uncomfortable with what they perceive as a governmental smoke screen.

\section{UK: Representative Diversity}

The diversity discourse in the BBC implies a slightly more nuanced perception of social reality, where "under-represented" groups such as disabled people and lesbians/gays are explicitly included in the definition as well as being actual targets of action. Use of the term under-represented actually allows for group conflicts and clashes of interest, which seems a more realistic view than the idea of consensual diversity. From an outsider's perspective, this most likely originates in Britain's imperialistic history and the post-imperial era, when citizens from all over the Commonwealth migrated into the UK and made it a multicultural society in a short time. These changes did not pass unnoticed, and of course there were (and are) conflicts and struggles for dominance between different groups. The special concern for disabled people seems to emanate from a traditional public service broadcasting issue - providing broadcasting services for the deaf (on television) was one of the earliest requirements placed on public service companies. Of course, there is great value to be gained from actually representing disabled people on screen - children in wheelchairs, people with prosthetics, with speech disabilities, with neurological handicaps and so on. Whether this will actually take place remains to be seen.

\section{US: "Majority" Diversity}

The American companies are very much interested in ethnic diversity, and direct their efforts towards the major ethnic minorities in the US: African Americans and Hispanics. These groups are politically important because they are large, and commercially important to the broadcasting companies for the same reason. Therefore, it makes sense to be observant of their demands on and expectations for American national television. However, it would be interesting to see some discussion of gender hierarchies within these ethnic groups and in relation to diversity efforts. That might induce a change in the perception of diversity, from an ethnic-minority issue to an issue concerning everybody in society.

\section{Public Service Diversity vs. Commercial Diversity}

The three public service broadcasters in the study (SVT, SR, BBC) all frame their actions for diversity in a decidedly national-political rhetoric, setting out to "reflect" and "represent" a multi-faceted nationwide audience in the name of fairness, equal participation and fully-developed democracy. However, there is a conspicuous difference between the wide scope of imaginable diversity and the considerably downsized, practically attainable diversity. The rather down-to-earth results of the companies' diversity work are not quite compatible with the high-flying ideals of their diversity policies.

The commercial companies, on the other hand, may be almost equally into nationalist rhetoric, but seem to escape the discrepancy between ideals and practice more 
lightly than do their public service competitors. This is mainly a consequence of their departure from narrower and more instrumental definitions of diversity, which sometimes may focus on only one minority group. Obviously, this commercial variety of diversity is not very efficient as political action, but that does not prevent it from being financially successful.

\section{Summary}

This study shows that the concept of diversity is subject to multiple definitions, depending on national culture and history. In Sweden, with its long tradition of gender equality, the demands for diversity are unanimous in any party-political context and occupy the public debate without ever really being debated or questioned. In the UK, the conception of diversity is more influenced by the risk of social conflicts, be they between groups or classes. In the US, diversity is used as a kind of counter-image to the melting pot idea, and serves the major minorities by ascribing them a particular status based on their great numbers. This illustrates the fact that representation has a political content - the largest minority groups are also (because of their size) the most politically influential, which means that they have the privilege of deciding who should be included in the diversity concept and who should remain outside.

This study also demonstrates the importance of media companies' organizational form and ideological objectives in influencing the modes and outcomes of their diversity work. Public service companies tend to set their idealist goals higher than do their commercial counterparts, something which risks leading to a steeper fall (and perhaps a greater loss of goodwill) when these goals and ideals are not attained.

\section{Conclusion: Diversity versus Gender Equality?}

My concluding and perhaps most important finding is, however, the fact that not one of the six media companies studied has chosen to publicize a gender equality policy on the web, or to explicitly include gender equality in their diversity work. Obviously, diversity and equal treatment of ethnic groups are considered more urgent in today's globalized society. Nevertheless, there is an impending risk that these concerns for ethnic diversity, no matter how justified they might be, will ultimately lead to a backlash for gender equality. To conclude this article, I therefore wish to argue for the importance of combining concerns for diversity with concerns for gender equality. This is important in several respects, politically as well as individually.

Politically, a "bifocal" view on diversity and gender equality, and an open acknowledgement of the complexity of these issues, might contribute considerably to the legitimacy of political decisions and actions. Structures of gender oppression may exist in the most ethnically diversified and tolerant surroundings, just as racism and sexism may occur together and create systems of double discrimination. Achieving the goals of both diversity and gender equality is no simple matter; it entails great difficulties and potential conflicts that must not be overlooked.

Individually, combining diversity and gender equality is important because people are not merely "immigrants" or ethnic representatives - they (we) are also always men or women, and thus intertwined in the treacherous web of opposing, diverging and converging power hierarchies. 
In postmodernist feminist and postcolonial theory, the concept of "intersectionality" has been used as an analytical tool to explore how various categories of power asymmetries - such as gender, ethnicity, race, sexual preference, age and social class interact in the construction of subjectivity as well as in the actual material conditions, and thereby contribute to social exclusion and political injustice (e.g., Crenshaw 1994).

Intersectional analysis focuses on the ways in which different power asymmetries construct each other, and is also concerned with keeping these power relations in focus rather than eliminating them, as discourses of multiculturalism and diversity often tend to do. In this way, the idea of intersectionality ensures that different orders of power and their interrelations are considered together.

In other words, intersectional thought enables - even presupposes - a state of conflict between different orders of power, and is of particular use in explaining hostility and inequality between social groups (de los Reyes \& Mulinari 2005). An intersectionality perspective allows for a critical analysis of the perhaps latent but still valid power hierarchies between different social categories, whereas a diversity perspective blurs hierarchies and inequalities in its efforts to create equal opportunities for all.

There is, as I stated in the beginning of this article, a constant risk of one concern outmaneuvering the other, often for political reasons. In my opinion, the only way to handle this dilemma is to discuss diversity and gender equality in relation to each other, in theory as well as in applied politics. This, however, seems seldom to be the case where media companies are concerned, despite the fact that media companies are committed to self-imposed regulations and codes of practice designed to promote un-biased journalism as well as democratic work places.

I wish to connect my final reflections on the dilemma of diversity versus gender equality to the idea of institutional racism, a kind of unintentional racism acting on a structural rather than an individual level, strongly attached to practical routines, personal hierarchies and unarticulated professional values (Downing \& Husband 2005: 150f). The concept is employed particularly in British politics, where it has been used to explain how racist discrimination is produced on a professional basis among people who do not embrace racist or extremist opinions in private. Perhaps the greatest advantage of the idea of institutional racism is that it places the responsibility for actual racist discrimination in all our laps - this is not a matter of a few bad apples behaving repulsively, this is a matter of social structures and cultural patterns in highly developed democratic societies that should be more aware of their own shortcomings. Driving home my line of argument, I would like to add a corresponding idea of institutional sexism, to shed some light on the risks inherent in foregrounding the problems of racism and other forms of discrimination against minorities in the diversity debate, while entirely leaving out the difficult issue of gender equality within as well as between different groups and social categories. I find it important to propose this concept as an analytical as well as a practical tool, convinced that mere awareness of the phenomenon as such could have precautionary effects. Determining whether or not the media companies studied here are examples of institutional sexism is not within the scope of this article. 


\section{References}

Anderson, Benedict (1991) Imagined Communities: Reflections on the Origin and Spread of Nationalism. London: Verso.

Benhabib, Seyla (2002) The Claims of Culture. Equality and Diversity in the Global Era. Princeton: Princeton UP.

Crenshaw, Kimberlé W. (1994) 'Mapping the Margins: Intersectionality, Identity Politics, and Violence Against Women of Color', in Fineman, Martha \& Rixanne Mykitiuk (eds) The Public Nature of Private Violence. New York: Routledge, pp. 93-118

De los Reyes, Paulina \& Diana Mulinari (2005) Intersektionalitet [Intersectionality], Lund: Liber.

Downing, John \& Charles Husband (2005) Representing 'Race': Racisms, Ethnicities and the Media. London: SAGE.

Giddens, Anthony (1991) Modernity and Self-Identity. Self and Society in the Late Modern Age. London: Polity Press.

Hall, Stuart (1997) Representation. Cultural Representation and Signifying Practices. London: SAGE.

Husband, Charles (2000) 'Media and the Public Sphere in Multi-Ethnic Societies', in Cottle, Simon (ed) Ethnic Minorities and the Media. London: Open University Press, pp. 199-214.

Scannell, Paddy (1989) 'Public Service Broadcasting and Modern Public Life', Media, Culture \& Society, Vol. 11 No. 2: 135-166

\section{Electronic sources}

http://svt.se, accessed 2005-02-22, 2005-03-24, 2006-01-09

http://www.bbc.co.uk, accessed 2005-02-23, 2005-03-24, 2006-01-10

http://www.cbsdiversity.com, accessed 2004-10-25, 2005-03-24, 2006-01-11

http://www.cbsnews.com, accessed 2005-03-24, 2005-04-25, 2006-01-11

http://www.fox.com, accessed 2004-10-22, 2005-03-24, 2005-04-22, 2006-01-11

http://www.itv.com, accessed 2004-11-01, 2005-03-24, 2006-01-10

http://www.sr.se, accessed 2005-02-22, 2005-03-24, 2006-01-09

KRISTINA WIDESTEDT, Ph.D., Senior Lecturer, Department of Journalism, Media and Communication, Stockholm University, P.O. Box 278 61, SE-115 93 Stockholm, widkri@jmk.su.se 